\title{
Short communication: Gelatinization and enzymatic hydrolysis characteristics relevant to digestion and analysis of glycogen granules isolated from ruminal protozoa
}

\author{
M. B. Hall* \\ US Dairy Forage Research Center, Agricultural Research Service, USDA, Madison, WI 53706
}

\begin{abstract}
Glycogen is an $\alpha$-glucan produced by rumen microbes from various feed carbohydrates. It may be digested ruminally or intestinally to provide nutrients. The physicochemical and enzymatic hydrolysis characteristics of microbial glycogen have not been described in detail, but do influence its conversion to absorbable nutrients in vivo, its nutritional comparability with plant starch sources, and its accurate analysis in vitro. The objectives of this study were to determine presence or absence of a gelatinization response and to describe enzymatic digestion characteristics of glycogen granules isolated from ruminal protozoa obtained from lactating dairy cows. Protozoal glycogen granules were determined to be $98.3 \%$ o-glucan. Granules displayed gelatinization, the breaking of hydrogen bonds between molecules or branches, at $65^{\circ} \mathrm{C}$ compared with purified wheat and corn starches, which initiated gelatinization at 50 and $65^{\circ} \mathrm{C}$, respectively. Digestion of ungelatinized samples with amyloglucosidase for $2 \mathrm{~h}$ at $39^{\circ} \mathrm{C}$ showed approximately 3 -fold greater hydrolysis to glucose for protozoal glycogen (25.2\% of dry matter; DM) than for wheat $(9.9 \%$ of $\mathrm{DM})$ or corn $(8.2 \%$ of $\mathrm{DM})$ starches. Based on enzymatic digestion results, protozoal glycogen may be more readily digested than intact corn or wheat starches and should be gelatinized or the hydrogen bonds otherwise disrupted to allow more complete recovery in enzymatic analysis.
\end{abstract}

Key words: rumen microbe, carbohydrate, glycogen

\section{Short Communication}

Microbial glycogen is an $\alpha$-glucan storage polysaccharide produced from various feed carbohydrates including mono- and disaccharides (Oxford, 1951), fructans (Thomas, 1960), and cellulose (Gaudet et al., 1992).

Received September 27, 2018.

Accepted January 30, 2019.

*Corresponding author: marybeth.hall@ars.usda.gov
Ruminal protozoa (Oxford, 1951) and ruminal bacteria (Gong and Forsberg, 1993) store insoluble granules of glycogen intracellularly. The negative $0.28-\mathrm{kg}$ intercept noted for ruminal starch digestibility in lactating dairy cows (Larsen et al., 2009) indicates that a portion of microbial glycogen produced in the rumen reaches the small intestine. Ruminal conversion to microbial glycogen provides an avenue for portions of otherwise readily fermentable carbohydrates to ferment more slowly in the rumen or pass to the small intestine and be used directly by the animal.

Protozoal polysaccharide granules (PPG) isolated from holotrich (isotrichid) ruminal protozoa contained only glucose in $\alpha-(1,4)$ and $\alpha-(1,6)$ linkages and had an average chain length of $22 \pm 1$ glucose residues per terminal glucose, a molecular weight of approximately 170,000 with negligible content of amylose, and a highly branched structure similar to amylopectin (Forsyth and Hirst, 1953). Comparatively, the branch chain lengths of amylopectin in wheat and normal corn starches are 41 and 24.4, respectively (Jane et al., 1999), with respective amylopectin molecular weights of 10.1 and $11.3 \times 10^{8}$ (Stevenson et al., 2007). Starches with shorter branch chain lengths can display lower gelatinization temperatures (Jane et al., 1999). Glycogen is hydrolyzed by enzymes that hydrolyze starch (Hall and Hatfield, 2015).

The enzymatic hydrolysis and physicochemical characteristics of glycogen from ruminal microbes have not been described in detail. These characteristics can provide insights regarding its digestion characteristics in the rumen and small intestine of the ruminant and for selection of appropriate analytical methods for its quantification. For example, it is unknown whether microbial glycogen possesses hydrogen bonding that is disrupted by gelatinization, though such bonding would make it more resistant to enzymatic hydrolysis (BeMiller, 2007) during digestion or laboratory analyses. A recommended method for analysis of microbial glycogen uses hot alkali to lyse the microbial cells (Daniels et al., 2007). This lysis may not only release 
glycogen from cells, but the alkali may also gelatinize (McCleary et al., 2002) glycogen granules and thus increase $\alpha$-glucan recovery during enzymatic analysis. If, like starch, PPG is hydrogen bonded, it would not be immediately available to attack by digestive enzymes, thus slowing or lessening its digestion in the small intestine or rumen, and gelatinization or other disruption would be essential for its accurate quantification in vitro. The objectives of this study were to determine whether isolated PPG underwent gelatinization and to compare its enzymatic hydrolysis characteristics with those of wheat and corn starches.

Gelatinization temperatures of samples were determined according to the method of Craig et al. (1989) based on that of Morgan (1940). Fifty milligrams of airdried corn starch (S4126, lot 90K0858, Sigma-Aldrich, St. Louis, MO), wheat starch (S5127, lot 74F-0657, Sigma-Aldrich), or PPG isolated from ruminal digesta of lactating dairy cows (Hall, 2016) was weighed into 8-mL screw-cap vials, with 4 vials prepared per sample. Deionized water $(5 \mathrm{~mL})$ was dispensed into each vial using a repeating positive displacement pipette (Eppendorf Repeater Plus, Eppendorf North America, Hauppauge, NY) and into 4 vials with no carbohydrate (reagent blanks); samples were shaken to mix. Of each set of 4 vials, 2 were maintained at ambient temperature $\left(\sim 23^{\circ} \mathrm{C}\right)$ and 2 were sequentially incubated in a circulating water bath for $30 \mathrm{~min}$ at each temperature: $37,50,57,65,70,75,80$, and $85^{\circ} \mathrm{C}$. All samples were vortexed for $5 \mathrm{~s}$ every $5 \mathrm{~min}$ during each incubation. After an incubation, vials were allowed to cool for $5 \mathrm{~min}$ on the bench. Reagent blanks were used to adjust the spectrophotometer (Spectronic 21, Bausch and Lomb, Rochester, NY) to a transmittance of $100 \%$ at $650 \mathrm{~nm}$ before measurements of samples. Samples were shaken to uniformly suspend the carbohydrate, and transmittance of the vial was read immediately. At initiation of gelatinization, transmittance of heated samples increased to depart from that of samples maintained at ambient temperature.

All samples and reagent blanks used in the gelatinization determination were then analyzed for enzymatic glucose release (Zinn, 1990). Individually, samples were vortexed to suspend the carbohydrate and $0.2 \mathrm{~mL}$ was transferred to a 2 -mL microfuge tube using a repeating positive displacement pipette. Sodium acetate buffer $(0.1 \mathrm{M}, \mathrm{pH} 5.0,1 \mathrm{~mL})$ with $4 \mathrm{U} / \mathrm{mL}$ amyloglucosidase (E-AMGDF, Megazyme International, County Wicklow, Ireland) was added to each tube. Microfuge tubes were vortexed and then incubated at $39^{\circ} \mathrm{C}$ for $2 \mathrm{~h}$ with vortexing every $40 \mathrm{~min}$. After incubation, samples were centrifuged at $12,000 \times g$ for $10 \mathrm{~min}$ at ambient temperature. Supernatants were analyzed for enzymatically released glucose using a glucose oxidase- peroxidase assay (Hall, 2015). Hydrolyzed $\alpha$-glucan was calculated as detected glucose $\times 0.9(0.9$ is the mass ratio of anhydroglucose to glucose).

Dry matter of samples was determined after drying overnight at $105^{\circ} \mathrm{C}$ in a forced-air oven. Total $\alpha$-glucan content of samples was determined in duplicate by an enzymatic-colorimetric starch assay (Hall, 2015).

Effect of heating on enzymatic glucose release was analyzed as a randomized complete block design. Fixed effects included substrate, heat treatment, and the interaction of substrate with treatment. Significance was declared at $P<0.05$. The Tukey-Kramer procedure for mean separation was applied to significant treatment effects. Analyses were performed using the MIXED procedure of SAS (version 9.3, SAS Institute Inc., Cary, NC). Because the gelatinization evaluation was intended solely to determine whether PPG gelatinized and other methods can give more precise values, no statistics were applied to gelatinization data.

Ratios of surface area to volume were calculated for starches and PPG, with granules treated as spheres. Surface area of a sphere was calculated as $4 \times \pi \times$ radius $^{2}$, and volume was calculated as $4 / 3 \times \pi \times$ radius $^{3}$, using reported measures (Jane et al., 1994; Hall, 2016) to estimate radii.

Increases in light transmittance associated with initiation of gelatinization represent dissolution of the crystalline and granular structures of $\alpha$-glucan granules as hydrogen bonds are broken. Temperatures at initiation of gelatinization determined for corn starch, wheat starch, and PPG were 65,50 , and $65^{\circ} \mathrm{C}$, respectively (Figure 1); heated wheat starch had barely deviated from the control at $50^{\circ} \mathrm{C}$. All replicate heated samples deviated from their unheated controls at the same temperature. The corn and wheat starch values are similar to those reported by Morgan $\left(1940 ; 65\right.$ and $55^{\circ} \mathrm{C}$, respectively), who used the same method as the present study, and to results determined by differential scanning calorimetry (corn starch, $64.1^{\circ} \mathrm{C}$; wheat starch, $57.1^{\circ} \mathrm{C}$; Jane et al., 1999) and by a blue dextran dye method for wheat starch $\left(48.8^{\circ} \mathrm{C}\right.$; Tester and Morrison, 1990). Oxford (1951) observed that PPG in distilled water "cleared at $70-80^{\circ} \mathrm{C}$ owing to the bursting of the granules," a point past the initiation of gelatinization. The gelatinization response of PPG indicates hydrogen bonding between the $\alpha$-glucan chains, perhaps similar to that of starch and similarly capable of impeding enzymatic hydrolysis.

Analyzed $\alpha$-glucan contents as a percentage of sample DM were (mean \pm SD) $98.3 \pm 0.01,99.5 \pm$ 0.57 , and $99.6 \pm 0.50 \%$ for PPG, wheat starch, and corn starch, respectively. The PPG preparation also contained a small amount of protein $(1.9+0.2 \%$ of DM) as determined with a Bradford assay (Hall, 2016). 
Table 1. Effect of heating on enzymatic release of glucose from $\alpha$-glucan substrates after $2 \mathrm{~h}$ of incubation (values are LSM of percentages of $\alpha$-glucan released $\left.^{1}\right)$

\begin{tabular}{|c|c|c|c|c|c|c|c|}
\hline \multirow[b]{2}{*}{ Treatment } & \multicolumn{3}{|c|}{ Sample type } & \multirow[b]{2}{*}{$\mathrm{SED}^{2}$} & \multicolumn{3}{|c|}{$P$-value ${ }^{3}$} \\
\hline & $\begin{array}{c}\text { Protozoal } \\
\text { glycogen granules }\end{array}$ & Wheat starch & Corn starch & & $\mathrm{S}$ & $\mathrm{H}$ & $\mathrm{S} \times \mathrm{H}$ \\
\hline
\end{tabular}

Although similar in composition, the $\alpha$-glucans differed in responses to enzymatic hydrolysis, the proxy used to assess digestibility differences among the pure $\alpha$-glucans via susceptibility to enzymatic attack (Table 1). For ungelatinized samples, PPG had approximately 3 -fold more enzymatic glucose release than did the starches $(P<0.01)$, and wheat starch had slightly more than corn starch $(P=0.02)$. For samples heated to $85^{\circ} \mathrm{C}$, which is past the start of gelatinization for all samples, PPG showed $1.6 \%$ less glucose release than wheat $(P$ $=0.03)$, but other pairings did not differ $(P>0.15)$.

Similar to the increased degradation of forage cellulose by rumen microbes in vitro as substrate particle size is reduced (Dehority and Johnson, 1961), a potential reason for greater 2-h enzymatic degradability of ungelatinized PPG than for the starches is the greater surface area relative to volume that is open to enzymat-

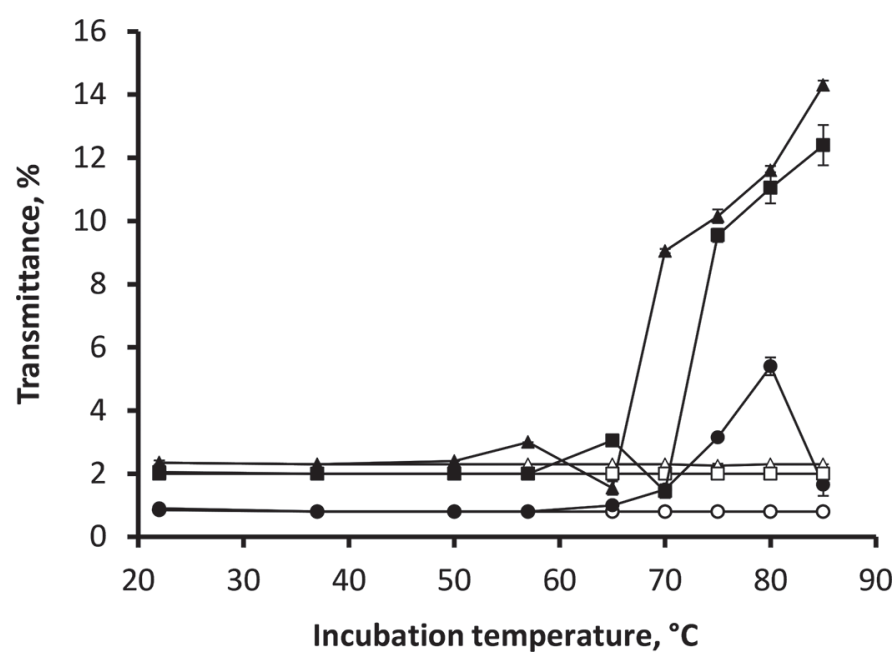

Figure 1. Responses of starches and protozoal glycogen granules to heating. Values are arithmetic means with SD error bars of transmittance measured at $650 \mathrm{~nm}$. Departure of transmittance values of heated samples from those of the controls indicates the initiation of gelatinization. Open symbols are unheated controls; closed symbols were heated. $\Delta, \boldsymbol{\Delta}=$ wheat starch; $\square, \boldsymbol{\square}=$ corn starch; $\bigcirc, \bullet=$ protozoal glycogen granules. ic attack. Among samples, PPG had the smallest, and smallest range of, reported diameter, length, or width at between 1 and $2 \mu \mathrm{m}$ (Hall, 2016), whereas starch granules are reported to vary between 5 and $20 \mu \mathrm{m}$ for corn and 2 and $36 \mu \mathrm{m}$ for wheat (Jane et al., 1994). Approximating granules to be spheres, the smaller the diameter, the greater the ratio of surface area to volume. Based on reported measures, approximate surface area:volume ratios for granules were 3 to 6 for PPG, 0.3 to 1.2 for corn, and 0.17 to 3 for wheat.

Given the limitations of in vitro evaluations to precisely predict response in vivo, that ungelatinized PPG was more readily enzymatically hydrolyzed than the starches suggests that intact PPG released in the rumen or small intestine may be more readily digested by enzymes than intact starch granules. The import of this finding is that, compared with unmodified plant starches, the glucose contained in PPG may be more rapidly available to support microbial growth ruminally or to be released for absorption in the small intestine.

Gelatinization or other disruption of hydrogen bonds appears to be essential to achieve more complete enzymatic hydrolysis for quantitative analysis of PPG. Commercially available beef liver glycogen is commonly used as a control sample in analyses for microbial glycogen, ostensibly due to their chemical similarities; however, it is water soluble and does not require gelatinization to achieve high $\alpha$-glucan analysis recovery values (Hall and Hatfield, 2015). Because they require gelatinization, plant starches may be preferable as control samples for analysis of PPG. For bacterial glycogen, isolated PPG or starches provide imperfect controls because they do not replicate the need for cell lysis to release glycogen from bacteria for analysis.

\section{ACKNOWLEDGMENTS}

Special thanks go to J. W. Pitas of USDA Agricultural Research Service US Dairy Forage Research Center (Madison, WI) for analytical assistance. This material is based on work supported with funding from 
USDA Agricultural Research Service. Mention of any trademark or proprietary product in this paper does not constitute a guarantee or warranty of the product by the USDA or the Agricultural Research Service and does not imply its approval to the exclusion of other products that also may be suitable.

\section{REFERENCES}

BeMiller, J. N. 2007. Starches, modified food starches, and other products from starches. Pages 173-223 in Carbohydrate Chemistry for Food Scientists. 2nd ed. AACC International Inc., St, Paul, MN.

Craig, S. A. S., C. C. Maningat, P. A. Seib, and R. C. Hoseney. 1989. Starch paste clarity. Cereal Chem. 66:173-182.

Daniels, L., R. S. Hanson, and J. A. Phillips. 2007. Chemical analysis. Section 18.3.4: Glycogen. Page 469 in Methods of General and Molecular Bacteriology. 3rd ed. C. A. Reddy, ed. American Society for Microbiology, Washington, DC.

Dehority, B. A., and R. R. Johnson. 1961. Effect of particle size upon the in vitro cellulose digestibility of forages by rumen bacteria. J. Dairy Sci. 44:2242-2249.

Forsyth, G., and E. L. Hirst. 1953. Protozoal polysaccharides. Structure of the polysaccharide produced by the Holotrich ciliates present in sheep's rumen. J. Chem. Soc. 2132-2135. (Abstr. 437.)

Gaudet, G., E. Forano, G. Dauphin, and A.-M. Delort. 1992. Futile cycling of glycogen in Fibrobacter succinogenes as shown by in situ ${ }^{1} \mathrm{H}-\mathrm{NMR}$ and ${ }^{13} \mathrm{C}-\mathrm{NMR}$ investigation. Eur. J. Biochem. 207:155162 .

Gong, J., and C. W. Forsberg. 1993. Separation of outer and cytoplasmic membranes of Fibrobacter succinogenes and membrane and glycogen granule locations of glycanases and cellobiase. J. Bacteriol. 175:6810-6821.

Hall, M. B. 2015. Determination of dietary starch in animal feeds and pet food by an enzymatic-colorimetric method: Collaborative study. J. AOAC Int. 98:397-409.
Hall, M. B. 2016. Technical note: A method for isolating glycogen granules from protozoa for further characterization. J. Dairy Sci. 99:1956-1958

Hall, M. B., and R. D. Hatfield. 2015. Comparison of methods for glycogen analysis of in vitro fermentation pellets produced with strained ruminal inoculum. J. Microbiol. Methods 118:147-151.

Jane, J., Y. Y. Chen, L. F. Lee, A. E. McPherson, K. S. Wong, M. Radosavljevic, and T. Kasemsuwan. 1999. Effects of amylopectin branch chain length and amylose content on the gelatinization and pasting properties of starch. Cereal Chem. 76:629-637.

Jane, J., T. Kasemsuwan, S. Leas, H. Zobel, and J. F. Robyt. 1994 Anthology of starch granule morphology by scanning electron microscopy. Starke 46:121-129.

Larsen, M., P. Lund, M. R. Weisbjerg, and T. Hvelplund. 2009. Digestion site of starch from cereals and legumes in lactating dairy cows. Anim. Feed Sci. Technol. 153:236-248.

McCleary, B. V., M. McNally, and P. Rossiter. 2002. Measurement of resistant starch by enzymatic digestion in starch and selected plant materials: Collaborative study. J. AOAC Int. 85:1103-1111.

Morgan, W. L. 1940. Pasting and identification of starches. Ind. Eng. Chem. Anal. Ed. 12:313-317.

Oxford, A. E. 1951. The conversion of certain soluble sugars to a glucosan by holotrich ciliates in the rumen of sheep. J. Gen. Microbiol. 5:83-90.

Stevenson, D. G., A. Biswas, J. Jane, and G. E. Inglett. 2007. Changes in structure and properties of starch of four botanical sources dispersed in the ionic liquid, 1-butyl-3-methylimidazolium chloride. Carbohydr. Polym. 67:21-31.

Tester, R. F., and W. R. Morrison. 1990. Swelling and gelatinization of cereal starches. I. Effects of amylopectin, amylose, and lipids. Cereal Chem. 67:551-557.

Thomas, G. J. 1960. Metabolism of the soluble carbohydrates of grasses in the rumen of the sheep. J. Agric. Sci. 54:360-372.

Zinn, R. A. 1990. Influence of steaming time on site of digestion of flaked corn in steers. J. Anim. Sci. 68:776-781. 